\title{
Multiple and superimposed Mongolian spots
}

\author{
Maria Letizia Musumeci, Francesco Lacarrubba, Cecilia Santagati, Giuseppe Micali
}

Department of Dermatology, University of Catania, Catania, Italy

\section{Correspondence to}

Professor Francesco

Lacarrubba,

francesco.lacarrubba@unict.it

\section{DESCRIPTION}

A 3-week-old Asian male newborn (42 weeks gestation, normal spontaneous vaginal delivery) presented for evaluation of multiple congenital greyish-blue macules. Dermatological examination showed a large grey to light-grey patch with undefined edges involving the sacrococcygeal and gluteal areas (size $9 \times 6 \mathrm{~cm}$ ); within this lesion, a superimposed, dark-blue, coin-shaped spot was observed (figure 1). Moreover, a small (size $1 \times 1.5 \mathrm{~cm}$ ) round greyish-blue patch was present on the right arm (figure 2). A diagnosis of multiple and superimposed Mongolian spots (MS) was made. The parents denied consent for a cutaneous biopsy.

MS, also known as congenital dermal melanocytosis, are benign, congenital, single or multiple bluish macules that usually affect healthy newborns and generally disappear during childhood. Although they are commonly observed in some racial/ethnic groups such as Asians and Native Americans, the presence of superimposed macules, as in our case, is a remarkable finding that has previously been very rarely reported. ${ }^{1}{ }^{2}$ Differential diagnosis mainly includes physical abuse, ${ }^{3}$ a condition excluded in our patient. As MS are histologically characterised by spindle-shaped melanocytes within the dermis, they are thought to be the result of the failure of melanocytes to correctly migrate from the neural crest to the developing epidermis. ${ }^{14}$ In our case, the simultaneous presence of the large light-grey patch and the superimposed small dark-blue spot might be due to two different waves of melanocytic migration resulting in a different amount of dermal melanocytes in the two

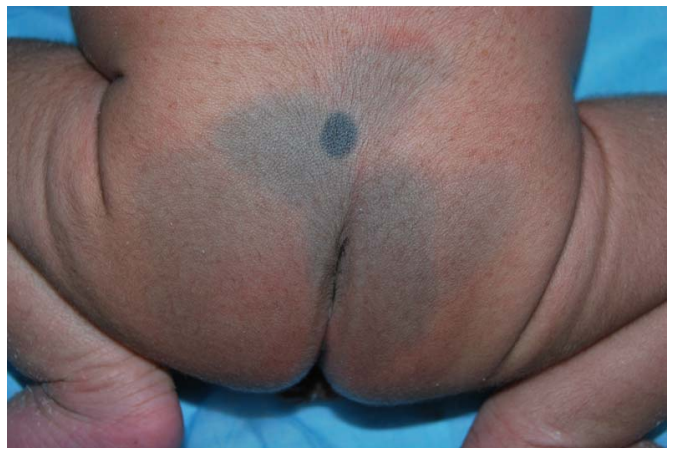

Figure 1 Large, grey to light-grey patch with undefined edges involving the sacrococcygeal and gluteal areas; within the lesion, a superimposed, dark-blue, coin-shaped spot may be observed.

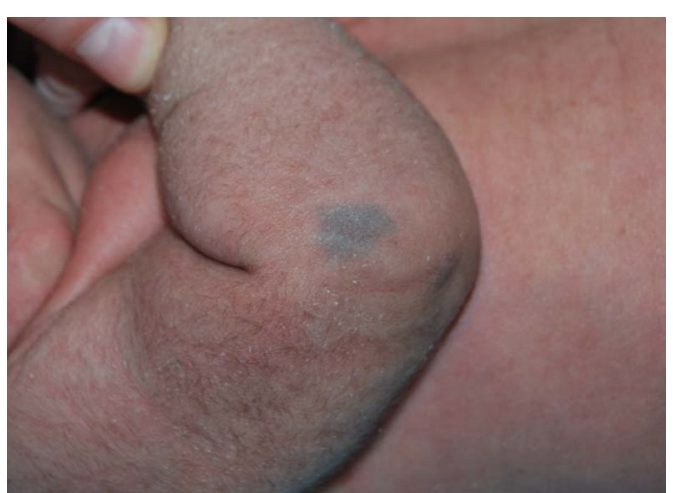

Figure 2 Small, round greyish-blue patch on the right arm.

areas. Alternatively, dermal melanocytes in the superimposed spot might have arrested more superficially during embryogenesis.

\section{Learning points}

- Mongolian spots are benign, congenital, bluish macules that usually affect healthy newborns and generally disappear during childhood.

- Although they are commonly observed in some racial/ethnic groups such as Asians and Native Americans, the presence of superimposed macules is a remarkable finding that has been rarely reported.

- Differential diagnosis of Mongolian spots mainly includes physical abuse.

Contributors All authors had access to the data, a role in writing the manuscript and approved the submitted version.

Competing interests None.

Patient consent Obtained.

Provenance and peer review Not commissioned; externally peer reviewed.

\section{REFERENCES}

1 Leung AKC, Robson WLM. Superimposed Mongolian spots. Pediatric Dermatol 2008:25:233-5.

2 Leung AKC, Kao CP. Extensive Mongolian spots with involvement of the scalp. Pediatric Dermatol 1999;16:371-2.

3 AlJasser M, Al-Khenaizan S. Cutaneous mimickers of child abuse: a primer for pediatricians. Eur J Pediatric 2008;167:1221-30.

4 Zembowicz A, Mihm MC. Dermal dendritic melanocytic proliferations: an update. Histopathol 2004;45:433-51.
To cite: Musumeci ML, Lacarrubba F, Santagati C, et al. BMJ Case Rep Published online: [please include Day Month Year] doi:10.1136/bcr-2013200740 
Copyright 2013 BMJ Publishing Group. All rights reserved. For permission to reuse any of this content visit http://group.bmj.com/group/rights-licensing/permissions.

BMJ Case Report Fellows may re-use this article for personal use and teaching without any further permission.

Become a Fellow of BMJ Case Reports today and you can:

- Submit as many cases as you like

- Enjoy fast sympathetic peer review and rapid publication of accepted articles

- Access all the published articles

- Re-use any of the published material for personal use and teaching without further permission

For information on Institutional Fellowships contact consortiasales@bmjgroup.com

Visit casereports.bmj.com for more articles like this and to become a Fellow 